\title{
The Complexity Vision for Online Development
}

\author{
Ana Maria Di Grado Hessel \\ GEPI Educational Program - PUCSP, Brazil \\ E-mail:digrado@uol.com.br \\ Ivani Catarina Arantes Fazenda \\ GEPI Educational Program - PUCSP, Brazil \\ E-mail: jfazenda@uol.com.br
}

\begin{abstract}
In the perspective of complexity, this Paper is on an experience of online development for school manager, in which an interdisciplinary attitude of partnership emerges. The characteristic of this development is a more complex and systemic vision, in which the school dynamics is regarded as an alive system, liable to be self-organized, a culture in permanent construction nourished by the interpersonal relations and collective work. It values Aesthetical sensibility in development, so fundamental for the projects committed with autonomy and emancipation, despite the fact this kind of Aesthetics has not been valued, but replaced by a more technical form of development. This approach offers the opportunity to experience a historical process, as it evolves contextualized knowledge. School managers and the researcher imbricate in an intersubjective relation while an attitude of interdisciplinary partnership emerges. Interactive online resources are used during the experience in which the narratives unveil the richness of the intersubjective communication and the intrasubjective process of construction and meaning of reality. During the development of this transdisciplinar research, I could perceive the movement of construction of the school managers' own experience, and reflect on my life experience, research my own practice learning about it, while continuously experiencing the two polarities: developing school managers and being developed as such.
\end{abstract}

Key Words: complexity; intersubjectivity; interdisciplinary; online development; school management. 


\section{INTRODUCTION}

There is a big concern on the part of Headmaster or Headmistresses of governmental schools to offer development to the school teachers, so that they can perform organizational changes in the school, aiming at education quality improvement.

Not always are the complaints related to the lack of competencies on the part of the School Manager to manage bureaucracy, but on the low ability in mobilizing the team for the intentional and educative action, conflict mediation, integration between school and community, articulation of personal and collective interests, cooperative atmosphere: in short, actions that require horizontal constructive processes, through communication and intersubjectivity.

Concerning the development of managers, Lück (2000) reveals that the programs of continuous improvement promoted by central organizations of the educational system offer contest which are too abstract for the professionals in development. In addition, they tend to consider the educational issues from a general perspective, distant from the school reality. Other times, the contents, besides not being contextualized, are not stimulating as they have a normative characteristic, once the learner is regarded as someone lacking abilities and competencies.

Thus, the managers in development cannot establish relation between what they study and what they experience. They do not have reference points to connect the contents to reality and construct meaning. The knowledge acquired from personal experience, built with meaning, are not taken into consideration, neither their life stories. The common characteristic of such kind of development is the distance between thinking and doing, two polarities which are not perceived as complementary parts of the same development process.

Proposals for development of managers are expected to be based on the conception of democratic management, social - historical production and the exercise of autonomy. In other words, development recognizing school as culture in process of constant construction, that focuses in processes instead of seeking for immediate results. The emancipatory thinking includes reflection in the development process, both on individual and collective journeys, once the managers can be the protagonists of their practice and development process.

Together with the programs of development with the presence of participants, there have been solutions in the online modality. Programs of development combining both, present participation and online participation have been offered at the federal and state levels, with governmental and private universities.

In this article, a transdisciplinar experience for the development of school managers is described, according to Hessel (2009), as it filters the particular reality through the principles of complexity. The focus is on the construction process of the development attitude of partnership, valuing the process of construction of meanings of the management action, imbricated in the life stories. This attitude of partnership is considered interdisciplinary, as it is an action category, according to the conception by Ivani Fazenda (2006). In this action - development research, we had the opportunity to investigate our practice in the development action, take an intervention and come to relevant learnings. 
This development was carried out at national level, by governmental institutions, with the aim to promote continuous improvement of the governmental school managers who are active, for an effective action of leadership and direction of the school community efforts, as a whole, for the achievement of the educational proposals. The project was implemented through a course, in the semi-presential modality, in 5 modules along 4 months, in a total of 100 hours.

Our participation was as a guide / developing professor of a group of 40 school managers of municipal and state schools of a state in Brazil. The action of the managers was followed through communication resources for online work, such as forums and daily narratives. The narratives showed to be an invaluable way to register the development process through intersubjective interactions. The attitude of partnership, on the part of the guide / developing professor, emerged as a way to exercise a guiding and singular action to the participants of the course. Besides containing indications of the peculiarity of each journey, the narratives of the managers conveyed the reflections and the significance of their practice.

Finally, we show the interpretation of the narratives of 3 managers, using the complex thinking references applied to school management.

\section{INTRODUCTION}

The expression School Management was introduced in education to replace the expression School Administration, aiming at encompassing new competencies for the school headmaster or headmistress, in the scenario of re-democratization of the governmental school. The function of the people running a school has been denominated school management to compensate the worn out terminology of administration which is associated to a technicistic interpretation, as well as to incorporate the political intentionality in the educational action. Lück (2000) explains that the difference between the terms is conceptual, once management is a new concept of educational organizations.

School management, in Brazil, is understood as a collective and participative process which runs the school encompassing the actions of decision taking, planning, execution, follow up and evaluation of the educational policy. At the practical level, the manager is expected to take over competencies for the promotion of collective work.

In this way, there will be encouragement for the participation of the subjects of his team and of the school community, assuring the construction and implementation of a pedagogical proposal, that is, a set of intentions, a collective pact.

The strengthening of democratization represents a change in the power network in the school. There is a displacement of axis: the vertical flow of centralized command gives way to more flexible horizontal relations. Power is not crystallized at the hierarchical levels, but it is distributed among the teams of work which assume responsibility for thinking and doing. Decision and action which used to be opposites in the hierarchical pyramid become complementary in the alive dynamics of the balance of polarities. The dichotomy - planning and executing - does not exist in the condition of mutual exclusion.

Protagonism of educators grows, as they share the same ideals among themselves. Their ideals are related to the change of the school reality, and they agree in assuming a common task, defined by negotiation of objectives. 
Work plans are not imposed anymore, neither top down nor outside inside, but are rather constructed, implemented and evaluated by the school teams. Democratic management at school, in essence, is not a practice that can simply be established, as it is a serf-organizing process, guided by the manager. At the conceptual level, the change of practice seems to make sense. However, at the level of action, the process is not mechanical, as social reality is extremely complex and the educational arena is not neutral.

In order to make this question clear, the discussion on school management will be amplified based on the conception of complex thinking by Morin (2005a, 2005b, 2005c), which encompasses the dialogic movement between linear and systemic thinking.

Linear thinking in management explains the prevalence of hierarchical control and of bureaucracy (bureaucracy). This kind of thinking, a hallmark of our time, tends to simplify reality so that it is understood and controlled. According to Mariotti (2007), it is competent for the treatment of mechanical and functional problems, but inefficient to face questions that require a systemic view. Linear thinking overuses reason, through rationalization, which is immediatistic, simplifying and reducing everything to simple causality.

The traditional model of school management, expression of the linear logic, strictly Cartesian and mechanistic, has its recent origins in the classical theory of administration. The ideas on work organization have the purpose to make business more competitive in the capitalist logic of profit generation and expansion, cost reduction and productivity.

The industrial productive process was rationalized with work division. The aim was to increase the company's efficiency through operational efficiency, that is, rational organization of work. This logic approach is also understood as mechanistic and is a consequence of the linear binary - Cartesian thinking.

The critical thinkers of the 20th century had an important role in denouncing the alienation present in the productive processes and in the social relations of such administrative models. As a consequence of this alienation, human beings were perversely deprived from understanding the nature and product of their work, as well as from perceiving themselves as human beings, the systemic part of a nature that includes them. The human dimension as a whole was eclipsed by the excessive importance attributed to a fragment of human potentiality, the working-force.

Until nowadays, the characteristic power structure at schools has been pyramidal with fragmentation of school work. As far as school organization is concerned, work division in technical - administrative tasks and pedagogical ones is a consequence of the value given to specialization at work. Functions and assignments are delimited by means of regulations, for the maximization of efficiency and effective hierarchical control. Hessel (2004) explains that, in addition to the horizontal specialization of the position of the school manager, there is the hierarchical aspect in the nets or governmental systems of education. Vertical specialization, also known as line administration, gives the superior in hierarchy formal authority, which is regulatory. The combination of hierarchy and knowledge, putting together the structure of power to the technical or operational one, has been the characteristic of the model - pyramidal structure at governmental schools. 
While linear thinking is efficient for the analysis of the parts of the whole, systemic thinking is important for the understanding of the interdependence of the parts. This kind of thinking is necessary for the manager, as it allows him to visualize school life beyond the bureaucratic routine and formal functional relations.

In Capra's view (1997), systemic thinking is a contextual kind of thinking, as this is its own essence. A system is a group of elements which are correlated. They maintain a form of organization and structure. The organization defines the identity of the system and expresses its configuration by the essential characteristics of its parts. The structure is defined by the relationship of the parts. The structure of a system changes during its existence, in continuous exchange of energy with the environment.

Work organizations can be conceived as dynamic nets, not linear ones, once the mechanicist paradigm is not enough to explain them. For Capra (2002), human organizations are like living systems. They cannot be controlled like machines, through instructions as they react to impositions. A machine can be operated with efficiency because its control is predictable. When it is broken it cannot change by itself and depends on maintenance. For example, a change projected by the administration and imposed to the organization tends to generate bureaucratic rigidity.

Considering an organization as a living being, we see the system is able to get self-organized, learn, change and naturally evolve, as its intrinsic characteristic is self-production. It is in permanent retroactive, circular movement of self-creation seeking for sustainability in the balance of two paradoxical forces: autonomy and dependence. However, it can create its own identity with its characteristic culture, understood as a set of meanings shared by the subjects in a historical dimension. That is how the emancipatory process is experienced.

Complex thinking encompasses linear thinking expressed in the bureaucratic matrix, as well as systemic thinking whose characteristic is the view of the whole. Both are dialogically opposites, that is, complementary opposites, according to the conception of complexity by Morin (2005a, 2005b, 2005c). Linear and systematic thinking are always present in the same reality. Prevalence of one over the other may represent an attitude of simplification in reading reality, if there is excess, for example, in particularization or generalization.

School organization reflects, in its own extend, all social complexity, as it is a cell of the social hologram and expresses the dynamics of the whole of which it is part. Like society, it is also a living organism which gets self-organized. In itself, the relations are ambiguous, being complementary and antagonic. Together with the movements of change, there are conservative forces, collaboration and resistance, order and disorder. Routine and emerging situations alternate, formal and informal relations flow in parallel, conflicts and ambiguity are natural in the game of convergences and divergences. One force always operates as an answer to the simplifying character of the opposite force.

A big challenge for the school manager is to embrace the coordination of bureaucratic activities and pedagogical ones in such a way to express a relation of interdependence. In practice, there is a division of tasks: the pedagogical activities tend to be under the supervision and total responsibility of the pedagogical coordinators, whereas the bureaucratic ones take all the time of the school manager. This scission is a consequence of a fragmented, reductionist view of the school teams. 
Thus, they base their actions exclusively in the assignments defined by the school regulations. What lacks is the view of the whole, perception of a systemic reality.

The pedagogic and bureaucratic tasks are imbricated in the democratic dimension and in complexity. The bureaucratic tasks are necessary to give support to the everyday life at school, as well as structure maintenance, project implementation, in others words, to vivify the purpose of the formative pedagogical process. Otherwise, it can be only linear and instrumental.

Besides the bureaucratic and routine activities, there are the planned actions. The first are predictable and remind us of rigidity, the others deal with uncertainties and the elements that emerge. According to Morin (2001), planning is a more strategic action, as it deals with unpredictability and flexibility, in opposition to a program where everything is done automatically.

Planning, in the complex and democratic dimension, is an action that depends on the participative movements. They emerge and are consolidated as the leaders and those who are leaded do not take position of excluded opposites. Management, in this case, is not exercised with authoritarianism, but rather, by gaining recognition and legitimation when there is respect and value to individuality and diversity. Balance between the polarities is maintained because the focus of changes remains in the interests and meanings. Significant disturbances act naturally in the organization, perceived as self-organizing systems, without the need of making a mechanical effort to keep them moving.

In modern organization, communication of intersubjective nature emerges in the core of the managemental practices, as there is a decrease in subordination relations and transmition of orders and directions. Interpersonal relations based on authoritarianism, obedience, vigilance and control are evaluated again and get new meanings in the model of partnership and collaboration.

\section{ONLINE DEVELOPMENT}

For the semi-presential course for government school managers' development, in which we were in charge of the development, there were individual and groups activities for learning in action, in a reflective and shared way. The dynamics adopted was reflection on the practice, articulated with the theories related to school management.

From the beginning, the school managers were asked to mobilize their teams of educators for the elaboration of an intervention strategic plan in the specific school realities, starting from a diagnostic evaluation of the school dimension, as for example: the school environment pedagogical practice, evaluation practice, democratic management access, students permanence, etc.

The communication resources, daily narratives and forum, had an important role in the support of intersubjectivity, integrating the participants of the course, debates on theory and practice, exchange of experience, and follow up of activities. The use of daily narratives allowed us to have a reserved contact with each of the managers. This communicative privacy was assured, and the participants knew that their narratives would be read and commented only by the professor guiding the development course...

In this development, the daily narrative were projected to catch, in the written registration, the impressions of the managers in the form of reflection on the own personal evolution process, as well as participation in the course. 
By using this virtual resource, we understood from the beginning that we could follow processual aspects in the development of each manager, mainly those related to their feelings, intentions and meanings. The daily narratives were perceived as instruments of intrasubjective reflection and intersubjective exchange, in which The attitude of partnership could be developed, in the form of guided messages.

The interdisciplinary attitude of partnership experienced during the development process of the managers emerged out of the value attributed to intersubjective exchange in daily narratives, based on the respect and recognition of the manager as an autopoietic being, who is product and producer of his/ her development and builds his being and doing recursively through the interaction with the others and the environment.

The concept of autopoiese described by Maturana \& Varela (1997) is the basis for this thinking. Every living creature is a living system, open and in constant exchange with the environment. He or she is paradoxally dependent and autonomous. Dependence on the environment in which one lives, as a result of the need to creatively get adapted in order to survive there, although not being determined by it. The environment only starts a series of structural changes in the living system, without directing them.

Autonomy comes with the ability the being has to get organized, in continuous cycles, that is, in cognitive interactions which are recurrent. Learning takes places so that the being can survive in the environment, changing the structure, but keeping stability in the inner pattern of organization. Thus, a living being cannot be controlled, just perturbed. Changes do not happen by imposition, but from inside out.

Our action for development was meant to grasp to context of the manager in development, understand it by means of the complex view and act in the congruence between both, the professional in charge of the development and the manager, using messages which guided for the consolidation of a democratic management practice. No formulae or immediate solutions were used from the linear thinking. The comments on the narratives of the participants were short and expressive, once we agree with Capra (2002) that they constitute 'significant forms to perturb the process'. In such cases, significant impulses are more pertinent then prescriptions of routes of instructions.

All the narratives were treated as parts of life stories and were read through the filter of complexity: moving between the whole and the parts, perceiving how the parts are related. It would make no sense to compare the narratives to make generalizations, as, according to Dominicé (1988, p.147), "each narrative reflects the way the journey was understood, the development defined and the process interpreted".

We were based in Fazenda's methodology $(2005,2006)$, considering that each one has a particular way of doing things and has to be recognized in the singular dimension, contextualized and imbricated in a life story. And, just as Josso (2004), we understand development as a process of self-development, when the subject becomes conscious of him/herself through of intersubjective approach. When we valued the narrative as a reference bringing knowledge of the self, we recognized the singularity of the development processes which have the power to transform "[...] life programmed in a social cultural way into a master piece to be built, guided by an increase of lucidity [...]" (p.58) 
We could perceive, in each narrative, the sense of a practice. As an ontological process, the narrative contains a peculiar perception of the reality, focused from a universe of belief built from experiences and values. It reveals a way of thinking and feeling the world, in which the subject perceives him/herself - a personal word. It is a means to produce meaning, as the experiences are composed of content and of a narrative artifice which shows a singular characteristic in its subtle shades. Different from speech, in which simultaneity of speech and thinking makes reflection difficult, the meaningful written registration is a secondary discourse which mobilizes thinking and rethinking of the object in question. According to Sabbag (2005), when the subject narrates facts which were experienced, he/she rebuilds his/her representation of reality bringing new meaning that can transform reality itself. Thus, one becomes conscious of the singular process of construction of identity, as people build differentiated meanings during life. This eternal self-construction and reconstruction of the being, in connection with the others, is the way to build individuality, autonomy and emancipation.

Fazenda (2003) stresses the importance of the narratives of experiences, as they are possibilities of innovation and interdisciplinar analysis, once they can generate new prospects. They are an opportunity to experience a new dialectic and contradictory movement, as they use both, registration and memory, for a new critical reading of the facts that had taken place. New meanings are constructed by the dialogic movement of the old and the new.

\section{REVELATIONS OF THE NARRATIVES}

We chose to use an interpretative analysis to understand each narrative in order to make explicit both, form and meaning. For this purpose, we used the universal elements to treat the realities narrated by Bruner (2001): narratives always have a central problem; action narratives contain states of intention; the understanding of the narrative is hermeneutic; there is a structure of consigned time in the narrative; there is also historical extensibility in each narrative.

We selected three narratives considering: the willingness of the authors to write them, besides the minimum expected quantity of narratives, that is, at the end of each of the 5 modules; and the willingness of the authors to register their reflections. To identify them we used fictitious names: Leila, Celia and Selma

Leila's narratives reveal her efforts to overcome the linear vision in the school reality. All her narratives are permeated by a strong feeling of fear in relation to the course, to the technology adopted, to the modality - semi-presential, and to the demands of work to be implemented in the school.

The conducting line or the central problem in all the narratives is the lack of confidence that makes her dependent to take any decisions. There is a belief that the difficulties found are because of material restrictions and people's lack of availability.

The narrative shows that Leila does not regard the school as a culture in construction, in which interests are shared, as well as latent meanings and history.

There are no indications of collective work based on communication and intersubjectivity. She lacks vision for the systemic thinking and the perception that she has the power to mobilize the team for participation, co-responsibility and autonomy. 
The structure of time of the narratives informs that they were produced in relevant moments, showing the change of direction in the course or in the school. At a given point, her lack of confidence was countered with sharing experiences, both virtual and presential. In the process, we guided Leila to the forums, where she can meet interlocutors willing to debate and share such problems. She feels revigorated, with her enthusiasm reestablished and she takes action at school and finds a way to create complicity among the members of her team.

With the knowledge she got in the course, she could implement evaluation processes, intervention actions, follow up and control, necessary to the administrative practice. However, the strategic meaning of such competencies could not be characterized as linear and mechanic, but rather, as a contextualized political action to be experienced, based in the understanding of the intersubjective nature of the participative practice.

Leila has difficulties that result from her linear view of management. There is a way to be covered by her and her team to overcome work fragmentation and adopt more participative practices. It is necessary to regularly experience processes of evaluation and become responsible for their actions. Communication channels must be opened through willingness to listen, share, exchange, etc. Relationships based on trust must emerge to sustain collective actions. Besides the technical knowledge, the social competence must be learned by the manageress.

Our partnership action helped the manageress give the first steps in the new direction. Whenever possible, she was encouraged to take part of forums, in order to enjoy the sharing of experiences.

As for Celia, her narratives reveal her systemic perception of the culture. The content of all her narratives shows that there is a central axis, around which all the narrative is developed, that is, the concern to get the participation of the school community. It was possible to grasp that, while reading all her narratives. In each one, Celia develops an only story of difficulty, hope, overcoming and success. In all the parts, the plot is repeated in cycles and the manageress renews her willingness to take new actions. The parts are contained in the whole.

Celia values human relations, rather than the vision of the functional tasks of the teachers. There is commitment with the construction of the school culture in friendly and affective levels, which minimize isolation and fragmentation of the school work.

She realizes that democratic management consists on the mediation of intersubjective relations and is attentive to the participation of all the sectors.

Her narratives assume a unique identity. She establishes an affective relation with her narratives calling them: 'My dear diary!', as well as by greeting them: 'My diary, good morning!' She feels comfortable to write and can express feelings and subjectivity.

Celia has a systemic perception of the collective work. She knows how important the participation of all the segments is, in the school projects. Her practice is built by overcoming challenges. In difficult circumstances, she tries some hypothesis and, strategically, finds ways to mobilize parents and educators, to be co-responsible for the educational action. Her purpose has being the involvement of the subjects assuring more commitment. In the online development, she learned the theory on plans, and felt the need to validate her practice and beliefs, through her narratives and affective identification with her narratives.

For this reason, our action of partnership emphasized revisiting her messages on the feedback about the way she guides her work. 
As for Selma's narratives, they reveal she regards school management in a complex way. She produced 12 narratives in journalistic style. The time structure in her narratives shows that the significant elements mentioned are close to the episodes of the course development, as they were built along the course. It is only from the history of the meetings with other managers that the protagonist finds reasons to speak and reflects about her school.

There is a transversal axis in Selma's narratives. The centrality of the whole is on the principles of collaboration and sharing, and her belief is that one can only learn with the other, listening and sharing. This essence which is found in each narrative, in each part of the whole, is the point of her narratives, as well as the motivation for her practice which unfolds in partnership attitudes. That suggests that the concern with her peers, in this moment, is her biggest concern.

Selma's considerations reveal a good understanding on the self-organizing process. She emphasizes the importance of collective work and ponders about the difficulties in developing it. By experience, she knows it is fundamental and that it has to be built through the dialogic movement: giving and receiving contributions. She understands ambiguity and the paradoxes of everyday reality at school, as she is conscious that facing them is a process, and she knows that it is possible to work with plans' linearity, as well as with the emerging elements from uncertainties. She understands herself and the others as autopoietic beings, able of learning in all the circumstances of life, both in professional practice and development periods.

Selma shows mastery in the conceptions on democratic management which seems to come from theoretical and practical reflections. She values collaborative learning and always comments on the importance of the moments of intersubjective sharing. In the narratives, she reveals the work dynamics of the school where she works, that is, the involvement of all the segments in the actions diagnosed and in action plans. Mobilization, co-responsibility and commitment on the part of the school team are indications that the experience on democratic practice is a reality, and that decision and action are imbricated in the field of collective work.

Our messages to Selma were invitations to play the role of an advanced peer and bring her contributions in the forums, with her experience and suggestions, once she enriched the course, when she shared her ideas on collaborative learning.

\section{CONCLUSIONS}

The transdisciplinar treatment of the reality in this research made it possible to reveal the procedural imbrication of the actors of the formative context.

The attitudes of partnership and respect to the formative journey of the school managers emerged with intention in the narratives, in the interlocution between the professor in charge of the development and the people in development. As we felt identified with the managers in development, we tried to establish, in a subtle way, the attitude of listening, friendship, without showing absolute truth, nor privileged knowledge.

In the basis of this intentional action, stands the belief that the manager must reflect on his/her doing for new meaning and construction of the organization action, articulation and mobilization in the political context of the school, in connection with the community. It is a creative process, taking the environment into consideration, which encompasses in Moraes 'words (2004, p.141) 'cooperation process, eco-construction and coevolution'. 
The attitude of partnership flows in the context, and that is why there is no fixed route in the dialogue between people of different journeys. There is a creative movement which is established in the congruence between the professor in charge of the development and the manager in development, which is revealed in the action based on respect and the ability to wait, as according to Fazenda (2003) it is by waiting that we can find the best moment for an intervention - an interdisciplinar principle.

It is an action whose movement is not reduced to the linear relation of cause and effect. It has a constructive character through interactions welcoming sharing. It is fed by retroactions, which act in return to the process which produced them.

The role of such retroactions is fundamental, as it may determine, inhibit, accentuates, change and transform the actions and interactions (MORIN, 2005a).

The interpretation of the narratives of the 3 school managers revealed the different moments experienced by each author, as well as our interdisciplinar attitude of partnership. We tried to reduce the feeling of lack of confidence and sensation of isolation experienced by Leila. As for Celia, we used massages of guidance, with the intention to help her understand her practice. The attitude adopted with Selma was that to try and consolidate her posture of partnership with the other managers.

The formative potential of the narratives, which initially showed as a tool adequate for intrasubjective reflection and intersubjective exchange, gained relevance as it allowed following the development process online. By following each manager, we could identify the way of their journeys, their strengths, needs, fears, the reflexive processes of re-elaboration of the experience.

In the interpretation of each narrative, we observed that they reveal, besides the different journeys, the essence of their authors. There is truly sense in all the doing, which is not at random, but built along life. By encouraging the written registration in the narratives, the professor in charge of the development can help she subject in development be conscious of his/her doing, rethink action and change posture, using the references and conceptions on management. In the online development, the written registration of the personal narratives has to be valued in the proposals for change of praxis, as it represents the possibility of taking care of an ethical and aesthetical knowledge, that is, of the soul of the technical knowledge.

A manager's development cannot lose sight of the manager as the subject of the development, his/her practice, vision of school reality and conceptions on management. At work, he feels challenged to mobilize the team do experience the democratic process, once the prevailing thinking at school is for reduction ideas, which fragment reality. In such conditions, power relations are kept hierarchical and bureaucratic aspects prevail on a more systemic view in which school is regarded as a living and self-organizing system fed by interpersonal relations. To deal with the contradictions of everyday life, it is necessary to have the view of complexity on the school organization, as management has to deal with predictability and uncertainty, too. Complexity encompasses the dialogic game of linear and systemic thinking.

We believe this research may contribute for the public institutions to reconsider their development models, which often follow the instrumental development model, in detriment of the Ethic Aesthetic development. 


\section{REFERENCES}

${ }^{1}$ BRUNER, Jerome. ( 2001) The Culture of Education. Porto Alegre: ArtMed. 2001.

${ }^{2}$ CAPRA, Fritjof. (2002) The Invisible Connections: science for sustainble life. S.P. Cultrix, 2002. Cultrix, 1997 . (1997) The Web of Life: a new scientific understanding of the living beings. São Paulo:

${ }^{4}$ DOMINICÉ, Pierre. (1998) What life has taught you. In: NÓVOA, Antonio; FINGER, Mathias. The (autho)biographic Method and the Formation. Lisboa: Pentaedro, 1988. pp.131-153.

${ }^{5}$ FAZENDA,Ivani. (org.) Interdisciplinarity in Teacher's Development: from theory to practice. Canoas: ULBRA, 2006, pp. 7-16. . (2005) Development of the Teacher-Researcher -30 years of research. Magazine E-Curriculum, São Paulo, v. 1, n. 1, dez-jul. 2005: available at <http://www.pucsp.br/ecurriculum>. Acessed on: 09 jan. 2009. . (2003) Interdisciplinarity: what is the meaning . São Paulo: Paulus, 2003.

${ }^{8}$ HESSEL, Ana Maria Di Grado. (2004) School Management and Technology: administrative and pedagogic, a complex relation . $154 \mathrm{f}$. Dissertation (Master in Educatin and Curriculum) - Pontifcial Catholic University - São Paulo, São Paulo.

(2009) School Managers' Development: interdisciplinar attitude in the online narratives. 150 f. Tese (Doutorado em Educação: Currículo) - Pontifícia Universidade Católica de São Paulo, São Paulo.

${ }^{10}$ JOSSO, Marie-Christine. (2004) Experiences on Life and Formation. São Paulo: Cortês, 2004.

${ }^{11}$ LÜCK, Heloisa.(2000) Prospects for School Management and Implications in Managers' Development , Brasília, v.17, n.72, p.11-33, fev/jun. 2000.

12 MARIOTTI, Humberto. (2007) Complex Thinking: applied to Leadership, Learning and Sustainable Development. São Paulo: Atlas, 2007.

13 MATURANA, Humberto ; VARELA, Francisco. (1997) On Machines and the Living Brings: autopoiesis - the organization of the living being. 3a ed. Porto Alegre: Artes Médicas, 1997.

${ }^{14}$ MORAES, Maria Cândida. (2004) Eco-systemic Thinking: education, leaning and citizenship Petrópopis: Vozes, 2004.

${ }^{15}$ MORIN, Edgar. (2005a) The Method 1: the nature of the nature. Porto Alegre: Sulina, 2005a. 16

17 . (2005b) The Method 2: the life of the life. Porto Alegre: Sulina. 2005b . (2005c) The Method 3: The knowledge of the knowledge. Porto Alegre: Sulina. 2005c

18 . (2001) Introduction to complex thinking. Lisboa: Instituto Piaget, 2001.

19 (2000) The well made mind: rethinking the reform, reforming the thinking. Rio de Janeiro: Bertrand Brasil, 2000.

${ }^{20}$ SABBAG, Sandra Papesky. (2005) The potential of the significant written register escrito significativo in the identity of the educator. São Paulo: Academia Editorial, 2005. 